\title{
Reexamination of the Korean plant names Changpo and Sukchangpo
}

\author{
Hyunchur Shin*, Michiyo Nomura ${ }^{1}$, Il Kwon Kim² and Seung-jic Hong ${ }^{3}$ \\ Department of Life Sciences, Soonchunhyang University, Asan 31538, Korea \\ ${ }^{1}$ Department of Tourism Business and Japanese, Jangan University, Hwaseong 18331, Korea \\ ${ }^{2}$ Division of Culture \& Arts, The Academy of Korean Studies, Seongnam 13455, Korea \\ ${ }^{3}$ Department of Chinese Language and Literature, Soonchunhyang University, Asan 31538, Korea \\ (Received 9 May 2017; Revised 30 May 2017; Accepted 8 June 2017)
}

\author{
식물명 창포와 석창포의 재검토 \\ 신현철* · 노무라 미찌요 ${ }^{1}$ 김일권 ${ }^{2} \cdot$ 홍승직 ${ }^{3}$ \\ 순천향대학교 생명시스템학과, ${ }^{1}$ 장안대학교 관광비즈니스일어과 \\ 2한국학중앙연구원 민속학과, ${ }^{3}$ 순천향대학교 중어중문학과
}

\begin{abstract}
The Korean plant names Changpo and Sukchangpo, including their related names Suchangpo and Kyeson, were somewhat confusingly used in both the Korean classics and even now. To clarify these names, the names written in the Chinese classics and the Korean classics were examined closely and compared to those of the modern flora of China and Korea. In the Chinese classics, Changpo and Sukchangpo were considered as conspecific with Acorus calamus, which has leaves with distinct veins, whereas Sukchangpo and Kyeson have leaves without distinct veins and are considered as $A$. gramineus. However, in the Korean classics, these names have been confusingly used thus far. Sukchangpo and Gyeson were considered as A. gramineus, and Sukchangpo and Changpo were considered as A. calamus, erroneously. Therefore, the following corrections are needed: plants having distinct leaf veins were named Changpo (A. calamus), and plants having vague leaf veins were named Sukchangpo (A. gramineus), and the names of Sukchangpo and Kyeson should be discarded to avoid confusion. In addition, to respond to the Convention on Biological Diversity, we propose a study to clarify the taxonomic identities of the plant names written in Chinese script and an examination of the Korean plant names listed in the Korean classics.
\end{abstract}

Keywords: Korean plant names, Korean classics, Changpo, Sukchangpo, Suchangpo, Kyeson

적 요: 식물명 창포, 석창포를 비롯하여 수창포와 계손 등은 우리나라 옛날 고전에서부터 혼란스럽게 혼용되어 왔으며 오늘날에도 마찬가지이다. 따라서 본 연구에서는 이들의 정확한 실체를 규명하기 위해서 중국 고전과 우 리나라 고전, 그리고 최근의 중국과 우리나라 식물지를 비교 검토했다. 중국에서는 창포와 석창포는 잎에 잎맥이 뚜렷하게 발달하는 Acorus calamus를 지칭하는 이름으로 사용되어 왔고, 수창포와 계손은 잎에 잎맥이 뚜렷하지 않은 A. gramineus 를 지칭하는 이름으로 사용되어 왔음이 확인되었다. 그러나 우리나라에서는 석창포와 계손은 A. gramineus로, 수창포와 창포는 A. calamus를 지칭했으나, 이름들이 혼용되어 온 것으로 확인되었다. 혼용에 따 른 혼란을 피하기 위해 계손과 석창포라는 이름을 사용하지 않고 A. calamus는 창포로, A. gramineus는 수창포로 부를 것으로 제안한다. 그리고 생물다양성협약에 대응하기 위해서는 한자로 표기된 식물명의 정확한 분류학적 실체를 규명해야 하며, 동시에 예부터 사용해왔던 한글로 표기된 식물명에 대한 연구가 필요함을 덧붙인다.

주요어: 한글 식물명, 고전, 창포, 석창포, 수창포, 계손

*Author for correspondence: shinhy@sch.ac.kr 
인류는 지구상에 태어나면서부터 자신에게 필요한 사 물을 인지하고 이들을 구분함과 동시에 사물에 이름을 붙 여왔다. 우리나라의 경우 신라에서 만들어진 것으로 알려 진 이두와 중국에서 만들어진 한자를 이용해서 식물 이름 을 기록해 왔다. 그러다 조선시대에 접어들어 세종 때 훈민 정음, 즉 한글이 만들어진 이후 한글로 식물의 이름, 즉 식 물명을 기록했다. 그러나 글을 쓰는 양반들은 훈민정음을 언문으로 간주하면서 여전히 한자로 식물명을 기록했다.

그러다 19세기 후반에 우리나라에 서양학문의 한 영역 으로 소개된 식물분류학이 새로운 학문으로 자리를 잡으 면서(Chung et al., 1986), 모든 식물에 학명을 부여하기 시 작했고, 일본이 동북아시아의 근대학문을 주도하면서 일 어로 된 식물명이 널리 퍼졌다. 그리고 광복 이후 모든 식 물명을 한글로 표기해왔으나, 처녀치마처럼 일본 식물명 을 그대로 번역한 경우도 많았다(Lee, 2005). 물론 한자로 된 식물명도 많이 있으나, 이들 식물명도 한자로 표기한 것이 아니라 한자의 음가를 한글로 표기했을 뿐이다. 그러 면서 식물분류학이 도입되기 전에 이미 우리나라에서 사 용되었던 많은 식물명에 대한 관심은 급속도로 사라졌다.

한반도에 자생하는 모든 식물에 학명을 부여하면서 동시에 한글 이름을 병기한 것은 1922년에 발간된 Mori 의 An Enumeration of Plants Hitherto Known from Corea 가 처음일 것이나 이 책에는 한글 식물명이 많은 편은 아 니다. 하지만 이후 1932년에 발간된 村田의『土名對照 鮮滿植物字彙』(Murata, 1932)에는 거의 모든 식물에 학명 과 함께 한글 이름이 병기되어 있고, 1937년에 발간된 정 태현 등의 『조선식물향명집』(Chung et al., 1937)에는 학 명과 한글 식물명이 나열되어 있었다. 이후 우리나라의 식물명은 『조선식물향명집』을 근거로 하여 증개정판이 발간되었는데, 정태현 등의 『조선식물명집』(Chung et al. 1949), 박만규의『우리나라 식물명감』(Park, 1949)이 있 으며, 최근 이우철은 『한국 식물명의 유래』 (Lee, 2005) 를 발간했다.

그런데 이들 자료들에 나열되어 있는 식물명이 모든 자 료에서 일치하지 않는 경우가 많아 한글 식물명 사용에 혼란이 야기되었고, 이를 해결하기 위해 국립수목원에서 소위 '국가표준식물목록(Korean Plant Names Index)'을 만 들었다. 그리고 국립생물자원관에서는 '국가생물종목록 (Biodiversity in Korean Peninsula)'을 만들기도 했다. 하지 만 국명의 명명규약은 별도로 없기 때문에, 기관마다, 학 자마다 각기 다른 식물명을 사용해도 문제는 없는 실정이 다. 이에 대해 유효출판물에 발표된 식물명의 경우에만 선취권을 인정해서(Lee, 2005) 사용하자는 주장도 제기되 었다.

하지만 유효출판물이라는 개념은 서양 학문인 식물분 류학에서 제기된 것으로, 개인 문집으로 손으로 필사된 우리나라 고전에 나오는 식물명에는 적용할 수가 없다. 더욱이 우리나라 식물명에서 가장 많은 수를 차지하는 것
이 전래되어 내려온 고유의 식물명임을 감안할 때(Lee, 2005), 더욱 유효출판물이라는 개념은 적용하기 어려운 개념일 것이다. 특히 국립수목원과 국립생물자원관에서 정리하는 표준식물목록과 국가생물종목록의 경우 일본 제국주의 시대 이전에 발간된 우리나라 고전에 나오는 식 물명에 대한 고려는 거의 없다. 예를 들어, 조선시대에 발 간된 『향약채취월령鄕藥採取月令』에 나오는 '창포(菖蒲)' 의 향명(鄉名), 즉 국명 '松衣竹(송의마)'는 국립수목원의 표준식물 관련 자료에 나열되어 있지 않다.

그런데『향약채취월령』말고도『향약집성방鄕藥集成 方』이나『동의보감東醫寶鑑』등과 같은 식물명과 관련된 수많은 자료가 조선시대에 편찬 또는 발간되었고, 특히 1820 년대 발간된 것으로 추정되는 유희의 『물명고物名 考』에는 약 4,200개에 달하는 식물명이 한자 또는 한글로 표기되어 있으나, 『물명고』에 대한 국어사적 연구만 수행 되었을 뿐 식물명에 대한 분류학적 고찰은 거의 이루어지 지 않고 있다. 최근 일부 학자들에 의해 조선시대에 편찬 된 자료들에서 한자로 기록된 식물명에 대한 분류학적 고 찰이 진행되고 있으나(Jin, 2015; Kim, 2015; Kong, 2016, 2017; Lee et al., 2016; Paeng, 2014a, 2014b, 2015; Shin, 2014; Shin et al., 2015, 2016), 이들 연구는 식물명의 분류학적 실 체 파악이 주된 목적으로, 과거 식물명과 현재 식물명의 일치 여부는 조사하지 않았다.

『향약집성방』은 1433 년에 편찬된 의학서로 약재로 사 용되는 식물 350 여 종류가 설명되어 있다. 그런데 이 책의 번역본 『국역 향약집성방』(Shin et al., 1989)에는 “菖蒲창 포) [鄉名: 석창포의 根萃] Acorus gramineus"라고 되어있 다. 창포라는 표제어가 의미하는 식물이 창포 Acorus calamus L.가 아니라 석창포 Acorus gramineus Solander ex Aiton라는 주장인 것이다. 따라서 본 연구에서는 『향약집 성방』에 나오는 '창포'의 분류학적 실체를 파악하고 동시 에 이들의 정확한 식물명을 규명하고자 했다.

\section{재료 및 방법}

『향약집성방』에 나오는 ‘창포’의 식물학적 실체를 파악 하기 위해 ‘창포'라는 이름이 기록된 중국 고전과 우리나 라 고전에서 이들의 용례를 검색했다. 중국 고전은 중국 고전의 원문 이미지와 텍스트 파일을 제공하는 ‘중국철학 서전산화계획(Chinese Text Project, 2017)'을 활용했다. 그리 고 중문으로 된 중국식물지(Flora of Chin in Chinese, 2017) 와 영문으로 된 중국식물지 웹사이트(Flora of Chin in English, 2017)도 참고했다. 국내 자료는 『향약집성방』원 본을 비롯하여, 『국역 향약집성방』(Shin et al., 1989), 『신 편 대역 동의보감』(Anonymous, 2006), 국사편찬위원회의 '한국사데이터베이스(Database in Korean History, 2017)'와 한국고전번역원의 '한국고전종합 $\mathrm{DB}$ (DB of Korean Classics, 2017)', 국사편찬위원회의 '한국역사정보통합시 
스템(Information System of Korean History, 2017)'에서 이들 식물명을 검색했고, 국내에서 발간된 각종 국명집을 비교 검토했다. 검색된 자료를 토대로 '창포'의 식물학적 특성 을 파악했고, 특성에 맞는 분류학적 실체를 파악해서 정 확한 학명과 국명을 확인했다.

\section{결과 및 고찰}

\section{중국 고전에 기록된 창포 특성}

중국의 경우, 300-400년경에 발간된 것으로 추정된 『포 박자抱朴子』에 “창포는 모름지기 돌 위에서 자라는 것을 얻어야 하며, 약 $3 \mathrm{~cm}$ 에 마디가 9개 있는 것이 좋으며, 자 주색 꽃이 피는 개체가 더욱 좋다(又菖蒲生須得石上, 一 寸九節已上, 紫花者尤善也.)”로 설명되어 있다. 그리고 977년에 발간된 『태평어람太平御覽』에는 “듣기에 중악(숭 산)의 석창포는 $3 \mathrm{~cm}$ 에 9개 마디가 있다(聞中岳有石菖蒲, 一寸九節.)"로 설명되어 있고, 1082년에 발간된 『증류본 초證類本草』에는 “진짜 창포 잎에는 잎맥이 뚜렷하고, 잎 이 칼날처럼 생겼다. (중략) 동측 계곡 측면에는 계손이라 는 것이 자라는데, 석상창포와 뿌리의 형태와 색이 매우 비슷하나 잎은 부들처럼 생겼고 잎맥이 없다. 일반 사람 들중 이 식물을 석상창포라고 하는 사람이 많은데, 잘못 이다(真菖蒲葉有脊, 一如劍刃, (중략) 東間溪側又有名溪 荪者, 根形氣色極似石上菖蒲, 而葉正如蒲, 無脊. 俗人多 呼此為石上菖蒲者, 謬矣.)”라고 설명되어 있으며, “수창 포는 계곡 얕은 곳이나 물 속에서 매우 많이 자라고 잎이 창포와 비슷하긴 하나 중심에 잎맥이 없으며, 이를 캐서 말리고 나면 가볍고 비워져 찌끼가 많아지는데, 특히 석 창포에 미치지는 못하여 약재로 적절하지 않다. 다만 가 루로 찧고 기름으로 개어서 옴이나 종기에 바른다(又有水 菖蒲, 生溪潤水澤中甚多. 葉亦相似, 但中心無脊, 採之乾 後輕虛多㵏, 殊不及石菖蒲, 不堪入藥用, 但可搗末, 油調塗 疥瘁.)”라고 설명되어 있다.

그리고 이시진이 1596년 편찬한 『본초강목本草綱目』에 는 “계곡에 자라며 잎이 수척하고, 뿌리가 길이 $50-75 \mathrm{~cm}$ 인 것은 수창포이며 계손이라고도 한다. 물 속 돌 틈에서 자라며, 잎이 칼 모양이며 잎맥이 있고, 파리한 뿌리에 마 디가 조밀하고 길이 약 $25 \mathrm{~cm}$ 를 넘은 것은 석창포이다(生 於溪澗, 蒲葉瘦, 根高二三尺者, 水菖蒲, 溪荪也; 生於水石 之間, 葉有劍脊, 瘦根密節, 高尺餘者, 石菖蒲也.)”라고 되어 있다. 한편 1716년 발간된 중국 한자 사전인 『강희자전康 熙字典』의 손(蓀) 항목에는 “계손은 석창포와 매우 유사 하나, 잎에 잎맥이 없다(溪荪, 極似石菖蒲, 而葉無倩.)”라 고 되어있다. 이상을 요약하면, 중국에서는 창포에는 여러 종류가 있음을 인지했고, 이 중 잎맥이 없으며 산간계곡에 서 자라는 종류는 수창포나 계손으로, 잎맥이 있으며 돌 위 나 돌 틈에서 자라는 종류는 창포 또는 석창포로 구분했고, 이중 석창포를 약으로 사용했다.

\section{우리나라 고전에 기록된 창포 특성}

중국의 문헌 자료와는 달리 우리나라 고전에 기록된 창 포의 특성은 시대별로 저자별로 조금씩 서로 다른 것으로 파악되었다. 이를 시대별로 살펴보면 다음과 같다.

(1) 1433년 편찬된 『향약집성방』에서는 창포를 “못가에 서 자라며, 근경 약 $3 \mathrm{~cm}$ 에 마디가 9개 있다(生池澤一寸九 節者)"라고 설명했다.

(2) 1454년에 편찬된 『조선왕조실록 세종지리지朝鮮王 朝實錄世宗地理志』의「강원도」편에는 석창포(石菖蒲)와 창포를 토산품으로, 「경기도」편에는 석창포를 토산품으 로 기록했다.

(3) 1530 년에 편찬된 『신증동국여지승람新增東國舆地 勝覽』의「경기 장단도호부」와「평안도 순천군」의 토산품 으로 석창포가 나열되었다.

(4) 1610 년 편찬된 『동의보감』에서는 창포를 “산골짜기 의 개울가 바위틈이나 자갈 밑에서 나고 자라며, 칼날처 럼 생긴 잎 가운데에는 맥이 뚜렷하고, 근경 약 $3 \mathrm{~cm}$ 에 마 디가 9 개 또는 12 개가 있다(生山中石澗沙磧上, 其葉中心 有青, 狀如劍刃, 一寸九笁者, 亦有一寸十二節者.)”라고 설 명했다. 이밖에『동의보감』에는 『증류본초』의 내용이 인 용되어 있는데, “수창(水菖)은 못에서 자라며, 창포와 비 슷하나 잎 가운데 잎맥이 없다(又有水菖, 生水澤中, 葉亦 相似, 但中心無釡.)”라고 설명했고, 『단심丹心』의 내용도 “손(蓀)은 잎에 맥이 뚜렷하지 않으며, 부추잎 같으나, 창 포는 맥이 뚜렷하며, 칼날같다(䒺無劍脊, 如菲葉者, 是也, 菖蒲有青, 一如劍刃.)”라고 인용했다.

(5)『승정원일기承政院日記』인조 3년 을축년(1625년) 2 월 3일자에는 “전라도 장성현에서만 임금이 쓸 석창포 가 난다(御用石菖蒲, 只産於全羅道長城縣.)”라는 기록 이 있다.

(6) 1772 년에 간행된 『기언릌ㅎㅁ에는 ‘남방 산의 바위 틈 에서 손초가 나오며, 계손이라고 한다. 그 줄기와 잎이 향긋 하고, 추위에 잘 견디고, 얼음과 눈 속에서도 늘 푸르다. 그 뿌리가 창포처럼 생겼는데, 다만 잎에 잎맥이 없을 뿐이다. 시골 의원들이 창포로 잘못 알고 사용한다(南方山石間, 產蓀草, 謂之溪蓀, 其荎葉香洌, 而寒, 水雪上常靑, 其根類菖 蒲, 特其葉無俸耳, 狛醫俁用之.)”라고 설명되어 있다.

(7) 17 세기 말에서 18 세기 초에 발간된 『산림경제山林 經濟』의 제 2 권 「양화養花」편에는 “석창포는 창포와 비슷 하나 잎이 좁고 짧다. 석창포를 약으로 쓰며 곳곳에 있다 (石菖蒲, 如菖蒲而細短, 藥用石菖蒲是也, 處處有之.)”라 는 설명이 있으며, 제4권 「치약治藥」 편에는 “석창포는 산중의 계곡 돌 틈에 나며, 잎에는 잎맥이 뚜렷하다. 수 창은 잎은 비슷하게 생겼으나 잎맥이 뚜렷하지 않으며, 약에 넣을 수 없다(石菖蒲, 生山中石澗沙磧上, 其葉中心 有脊. 水菖, 葉亦相似, 而但中心無脊, 不堪入藥.)”고 되어 있다. 
(8) 유희는 1820 년경 그때까지의 정보를 종합하여 『물 명고』를 편찬하면서, 석창포는 “물속 돌 틈에서 자라며, 잎 에는 맥이 뚜렷하거나 잎이 부추잎과 비슷하며 뿌리는 숟 가락 자루와 비슷하다(生水石間, 葉有劍春者, 又有葉似 非根似题柄者.)”라고 설명했고, 창포는 “한 종류가 아니 다(種類不一.)”라고 설명했다. 또한 계손(渓蕬)은 “계곡에 서 자라며 잎은 가늘고 뿌리는 얕게 자란다(生於溪間葉瘦 根高.)”라고 하면서 난손(蘭孫) 또는 수창포(水菖蒲)라고 부른다고 설명했다.

이상을 정리하면, 창포라고 불렀던 식물들은 대조되는 두 부류의 특성을 지닌 것으로 추정된다. 즉, (1) 생육지로 못에서 자라는 종류와 산간 계곡에서 자라는 종류, (2) 잎 에 잎맥이 뚜렷한 종류와 그렇지 않은 종류, (3) 잎이 좁고 짧은 종류와 그렇지 않은 종류, (4) 상록성인 종류와 낙엽 성인 종류, (5) 전국적으로 분포하는 종류와 남쪽에 분포 하는 종류 등이다. 그리고 조선시대에 창포라고 부르는 종류는 창포를 비롯하여 수창포, 석창포, 손(또는 계손) 등 여러 이름으로 불렀는데, 조선시대 초기에는 어떻게 구분 했는지 확인되지는 않지만, 『세종지리지』에 토산품으로 창포와 석창포만 나온 것으로 보아 석창포와 창포 두 종 으로 구분했던 것으로 보인다.

그런데, 중국 고전과 달리 우리나라 고전에서는 창포 종 류에 대한 설명이 명확하게 대립되지 않고, 서로 부분적 으로 겹친 것으로 파악되었다. 자생지를 살펴보면, 창포 는 못에서 자라거나(『향약집성방』) 산간 계곡에서(『동의보 감』), 석창포는 산간 계곡에서, 수창포는 못에서, 그리고 손은 산간 계곡에서 자라는 것으로 설명되어, 창포와 수 창포의 자생지가 겹치면서, 창포는 못이나 산간 계곡 모 두에서 자라는 것으로 조사되었다. 분포지를 살펴보면, 창 포는 강원도에(『세종지리지』), 석창포는 강원, 경기, 평안, 전라를 비롯하여 전국 각지에서(『세종지리지』, 『승정원일 기』, 『산림경제』「양화편」), 손은 남쪽 지방에(『기언』) 분포 하는 것으로 파악되었다. 잎의 특징으로 잎맥의 발달 여부 를 살펴보면, 창포와 석창포에는 발달하나(『동의보감』, 『산 림경제』「치약편」, 『물명고』) 수창포와 손은 발달하지 않으 며(『동의보감』, 『기언』), 석창포와 손의 잎은 가늘고 짧은 것 으로(『산림경제』「양화편」, 『물명고』) 조사되었다.

이러한 혼란은 (1) 『동의보감』에서 못에서 자라는 종 류(중국에서는 석창포의 자생지임)와 산간 계곡에서 자 라는 종류(중국에서는 수창포의 자생지임)를 하나의 이 름 창포로 설명했고, (2) 『산림경제』「양화편」과「치약편」 에서 설명한 창포 종류도 잎이 가늘고 짧은 종류(중국에 서 수창포라고 부르는 식물의 특성임)와 잎맥이 발달한 종류(중국에서 석창포라고 부르는 식물의 특성임)가 서 로 다른 식물임에도 한 이름, 석창포로 설명했고, 그리고 (3) 전남 장성에 자라며 임금의 약재로 사용되었다는 석창 포의 경우 잎맥이 없으며 잎이 좁고 짧으며 상록성인 특성 을 지니고 있어(Park, 2006) 손(또는 계손)과 같은 창포 종류
임에도 불구하고 중국에서 잎맥이 발달해서 석창포라고 부른 식물과 동일시한 결과 발생한 것으로 추정된다.

\section{창포의 분류학적 실체}

중국에서는 잎맥이 없는 수창포의 경우 금전포金錢蒲 라는 중국명으로 A. gramineus라는 학명을 쓰거나(영문판 중국식물), 석창포라는 이름으로 A. tatarinowii Schott라는 학명을 사용했고, 잎맥이 있는 것으로 기록된 석창포의 경우 그냥 창포菖蒲라는 이름을 사용했고, 학명은 $A$. calamus를 사용했다. 단지 영문판 중국식물지에는 $A$. tatarinowii가 A. gramineus와 같은 종으로 처리되어 있다. 그리고 중문판 중국식물지에는 “이시진이 창포 정품이라 고 인정한 종은 물과 돌 사이에서 자라고 잎에 잎맥이 있 고, 마른 뿌리에 마디가 촘촘하고, 키는 $1 \mathrm{~m}$ 이상 자라는 석창포이다(李时珍认为菖菖蒲正品应为 “生于水石之间, 叶具剑春, 瘦根节密, 高尺余者, 石菖蒲也”.)”라고 설명되 어 있어, 중국에서는 잎맥이 있는 석창포를 단순히 창포 라고 부르는 것으로 생각된다. 대신 잎맥이 없는 종류들 은 중문판 중국식물지에서는 금전포金钱蒲 A. gramineus, 장포창포長苍菖蒲 A. rumphianus S.Y. Hu, 석창포石菖蒲 $A$. tatarinowii 등 3 종으로 구분했으나, 영문판 중국식물지에 서는 이들 모두를 통합하고 중문명으로는 금전포金錢蒲, 학명으로는 A. gramineus를 사용했다. 영문판 중국식물지 에서는 석창포라는 이름을 사용하지 않았는데, 석창포라 는 이름이 주는 혼란을 피하기 위함으로 추정된다.

국내에서는 중국에서와는 달리 잎맥이 있는 종류에 창 포라는 국명과 A. calamus라는 학명을, 잎맥이 없는 종류 에 석창포라는 국명에 A. gramineus라는 학명을 사용하고 있다(Ko, 2007). 잎맥이 없는 것으로 알려진 수창포나 손 에 잎맥이 뚜렷한 것으로 알려졌던 석창포라는 국명에 $A$. gramineus라는 학명을 사용한 것인데, A. gramineus에는 잎 맥이 뚜렷하지 않다. 이렇게 된 이유는 확실하지는 않으 나, 우리나라에서 학명과 국명을 같이 표기하기 시작한 Mori (1922)의 An Enumeration of Plants Hitherto Known from Corea에 석창포라는 국명에 A. gramineus를 사용한 것으로 되어있고, 이후 Murata (1932), Chung et al. (1937) 등도 이러 한 견해를 따랐고, 오늘날까지 이어졌기(Choi, 2011) 때문 으로 풀이된다. Mori (1922)가 어떤 근거로 잎맥이 없는 것 으로 알려진 ‘수창포'나 '계손’이라는 이름을 버리고 잎맥 이 있는 종류로 보고된 ‘석창포’라는 이름을 사용했는지 는 알 수는 없는 상황이지만, Mori의 견해를 무비판적으 로 수용하고 있는 실정이다.

단지 우리 고전에 나오는 창포, 석창포, 수창포, 손의 분 류학적 실체를 문헌별로 살펴보면 다음과 같다. (1)『향약 집성방』의 창포는 오늘날의 창포(A. calamus) 또는 창포속 (Genus Acorus) 식물일 것이며, (2)『동의보감』의 창포는 두 종류인데 산중 계곡에 자란다는 창포는 오늘날의 $A$. graminues일 것이며, 잎맥이 뚜렷한 창포는 오늘날의 창포 
(A. calamus)일 것이며, 수창과 손은 오늘날의 A. gramineus 일 것이다. (3) 『승정원일기』에 나오는 전라도 장성에 분포 하는 석창포는 오늘날의 A. gramineus이며, (4)『기언』에 나 오는 남쪽 지방에 자라며 상록성인 손은 오늘날 $A$. gramineus일 것이다. 한편 (5) 『산림경제』「양화」편에 나 오는 잎이 좁고 짧은 특징을 지닌 석창포는 오늘날의 $A$. gramineus일 것이나, 「치약」편에 나오는 잎에 잎맥이 뚜렷 한 석창포는 오늘날의 창포(A. calamus)일 것이다. 그리고 (6)『물명고』에 나오는 석창포는 오늘날의 창포(A. calamus) 이며, 손은 오늘날의 A. gramineus일 것이며, 창포는 창포 속(Genus Acorus)를 지칭한 것으로 추정된다.

\section{약재명으로써 창포}

창포는 약재로서 중국 후한 시대에서 삼국 시대로 넘어 가는 시기에 편찬된 것으로 알려진 『신농본초경神農本草 經』에 처음 나오는데, “못에서 자라는 것(生池澤)”으로 기 록되어 있으며, 총기를 더해주는 대표 약재로 동의보감에 서 총명탕의 주재료로 사용된다(Jung et al., 1999; Jo et al., 2013). 그러나 『신농본초경』이전인 전한 시대(기원전 2069)에 편찬된 『설원 說苑』에 “문공은 창(昌)의 뿌리를 절인 것을 잘 먹었는데, 본초(本草)에서는 창(昌)은 바로 창포 (菖蒲)이다(文公好食昌本䓚, 本草即菖蒲.)”라는 설명도 나온다. 아주 오래 전부터 창포를 즐겨 먹거나 약재로 사 용했던 것으로 추정된다. 그리고 창포 종류를 수창포와 석창포로 구분했고, 한때 수창포는 약재로 사용하기에 적 합하지 않은 것으로 간주되었다. 즉 『증류본초』에 따르면 수창포는 약으로 쓰기에 부적합한 것으로 되어있다. 그럼 에도 불구하고 현재는 이들 모두를 구분하지 않고 약재로 사용하고 있는데, 이 역시 『증류본초』기록에 의존하는 것 으로 보인다. 즉, 『증류본초』에는 “지금 약방에서 파는 상 품은 두 가지를 섞어놓은 것이 많은데, 구분하기 매우 어 렵다고 기록되어 있다(今樂肆所貨, 多以兩種相雜, 尤難辨 也.)”. 약재명으로 사용할 경우 이들의 뿌리만을 '창포'로 불렀던 것으로 보인다.

우리나라에서도 창포 종류를 식용 또는 약용으로 이용 해왔으나, Mori (1922) 이후 잎맥이 있는 석창포를 창포로 부른 반면, 잎맥이 없는 수창포를 Acorus gramineus라는 학 명으로 부르다가 석창포라는 이름으로 부르게 된 것으로 보인다. 특히 『동의보감』에 “菖蒲 셕창포”라고 언급된 부 분에 따라 잎맥이 없으나 Mori가 석창포라고 잘못 부른 $A$. gramineus를 학명과 국명에 대한 검토를 하지 않고 석창포 로 부르면서 창포(A. calamus)보다 좋은 약재로 사용한 것 으로 보인다. 특허청에서 운영하는 한국전통지식포탈에 는 “석창포(石菖蒲)”라는 약재명에 “Acorus gramineus”라 는 학명이 병기되어 있고, A. calamus를 약재명으로 수창 포라고 잘못 부르고 있는 실정이다(Beom et al., 2007, 2010; Kim and Lee, 1987; Yu, 2012). 그러나 최근 A. graminues 뿐 만 아니라 A. calamus도 모두 약재로 사용하고 있으며(Jo et al., 2013), A. calamus(수창포라는 국명을 사용함)의 효능이 A. gramineus(석창포라는 국명을 사용함)보다 상대적으로 높다는 보고도 있어(Choi, 2011), 약재명으로는 혼란을 피 하기 위해 수창포, 석창포, 창포 등의 개별 식물명을 사용 하는 것보다는 이들을 모두 포괄하는 ‘창포'를 약재명으로 사용하는 것이 더 좋을 것으로 생각된다.

\section{창포와 석창포라는 국명}

창포는 일반대중이 향약채취에 직접 편리하게 활용하 려고 1431년 간행된 『향약채취월령』에 ‘松衣厅(송의마)' 라는 향명(鄉名), 즉 국명으로 소개되어 있다. 그리고 이 이름은 ‘숑이모'의 표기로 간주되는데, 이름의 근원은 불 명확한 것으로 알려져 있다(Jo, 1982). 이밖에도 1251년에 간행된 『향약구급방』에는 '消衣个(소의마)', 1489년에 간 행된 『구급간이방언해救急簡易方颜解』에는 ‘돌서리옛숑 의맛불휘’, 1790 년에 편찬된 『광제비급 향약단방치험 廣 濟秘菔 鄉藥單方治驗』에는 ‘돌밧히난’과 같은 국명도 나 열되어 있다(Son, 1996). 그리고 창포의 이름인 “松衣' (송 의마)'와 '消衣竹(소의마)'는 'soriima'로 읽힌다는 주장도 있다(Lee, 1994). 이밖에 계손이나 손, 수창포 등과 같은 국 명들은 1930년대 이후 발표된 창포, 장포, 향포, 왕창포(이 상 창포), 석창포, 석장포, 석향포, 창포, 애기석창포, 바위 석창포(이상 석창포)와 같은 국명들과는(Lee, 1996) 전혀 다른 것들로 지금까지 식물분류학자들에게 소개되지 않 았던 이름들이다. 식물분류학이라는 학문에 학명 이전의 각 나라나 지역의 식물명에 대한 연구도 포함된다면, 우 리나라 식물분류학계에서도 이들 식물명에 대한 연구를 체계적으로 수행해야만 할 것이다.

\section{창포와 수창포라는 국명 제안과 제언}

본 연구 결과 우리 고전에서 사용한 창포와 석창포라는 식물명은 사람들에 따라 서로 다르게 사용되어 왔음을 확 인할 수 있었다. 따라서 고전에 나오는 이들 식물명은 어 떤 의미로 어떻게 사용했는가에 따라 각기 다르게 해석해 야만 할 것이다. 특히 창포처럼 약재명과 식물명을 혼용 해서 사용한 경우에는 더욱 더 유의해야만 할 것이다. 단 지 과거에 사용했던 이름과 현재 사용하는 이름에서 발생 하는 혼란을 피하기 위해서 잎맥이 발달한 A. calamus는 국명으로 “창포”를, 잎맥이 발달하지 않은 A. gramineus는 과거에 잎맥이 발달했던 식물로 간주했던 석창포라는 국 명 대신 “수창포”라는 이름을 사용할 것을 제안한다. 영문 판 중국식물지에서도 석창포라는 이름은 사용되지 않았 는데, 이러한 혼란을 피하기 위한 것으로 풀이된다. 그리 고 약재명으로는 창포나 석창포 또는 수창포를 구분하지 않고 '창포'로 통일하는 것이 바람직할 것으로 보인다. 국 내에서는 석창포가 더 우수한 약재로 알려져 있으나, 오 늘날 창포라고 부르는 종보다 우수한 약재라고 처음 언급 했던 『증류본초』의 석창포는 오늘날 부르는 석창포와 다 
른 창포이며, 창포 종류들 사이에서 큰 약효 차이가 없는 것으로 파악되었기 때문이다.

한편 최근 생물다양성협약과 관련해서 많은 나라에서 전통지식에 대한 관심이 높아지고 있다. 그리고 우리나라 에서도 이러한 추세에 맞추어 한자로 기록된 옛 문헌에 나오는 식물들을 현대 식물분류학 관점에서 파악하려고 노력하고 있다. 최근 국립생물자원관에서 이러한 추세에 맞추어 『해제로 보는 조선시대 생물자원』(Chung et al., 2016)이라는 4책으로 된 책자를 발간하기도 했고, 일부 연 구자들에 의해 한자 식물명의 실체가 규명되고는 있다. 그럼에도 아직도 많은 한자 식물명의 실체는 파악되지 않 거나 연구 결과가 서로 상충되고 있어, 이에 대한 연구가 시급히 진행되어야만 할 것이다. 한 가지 사례로, 수유(茱 莫)라는 식물명에 대해 오수유(吳茱英, Evodia rutaecarpa (Juss.) Benth.)라는 주장(Shin, 2014)과 식수유(食茱英, Zanthoxylum ailanthoides Siebold et Zucc.)라는 주장(Paeng, 2014a)이 거의 동시에 제기되기도 했다.

특히 이런 연구에서 국명에 대한 논의는 이루어지지 않 고 있는데, 국명에 대한 연구는 식물과 관련된 우리 문화 를 올바르게 재해석할 수 있으므로 국명의 변천 과정에 대한 연구도 병행되어야만 할 것이다. 예를 들어 『향약구 급방』에는 도라지가 道羅次로, 나리가 犬乃里花로 표기되 어 있고, 우리나라에서만 金達萊를 진달래로 읽고 있었음 에도 불구하고(Lee, 1993), 이러한 국명은 국내 명감류나 도감류에 소개되어 있지 않은 실정이다. 분류학이라는 학 문을 서양학문으로 규정하면서 우리 전통 지식과 관련된 식물분류학적 지식은 거의 사장되었는데, 이를 되살리는 일도 시급한 일이 될 것이다. 한편 국명을 선취득권(Lee, 2005)만으로 국명이 발표된 우선순위를 따져 사용해야 한 다면, 현재 사용하는 식물명보다는 훨씬 이전부터 불러왔 던 이름들을 사용해야만 할 것이다. 그러나 옛 이름이 발 견되었다고 해서 당장 사용하는 것이 아니라 학계에서 이 를 널리 연구하고 내린 결론에 따라야만 할 것이다.

\section{Acknowledgments}

This study was conducted with the support of the Academy of Korean Studies (in-depth study of Korean culture, 2017).

\section{Literature Cited}

Anonymous, 2006. New Translation of Dongui Bogam (Principles and Practice of Eastern Medicine) Tangaekpyeon (Remedies). Buminmunhwasa, Seoul, 3987 pp. (in Korean)

Beom, H.-J., D.-J. Kang, B -D. Lee, J. Shon, J. S. Im and J.-B. Eun. 2007. Physicochemical characteristics of powder from hot air and freeze dried leaves and roots of Acorus calamus L. Journal of the Korean Society of Food Science and Nutrition
36: 1451-1457. (in Korean)

Beom, H.-J., R. Kim and H. S. Kim. 2010. The physicochemical properties of sweet flag (Acorous calamus L.) and the effects on skin protection of its ethanol extracts by UVB. Korean Journal of Aesthetics and Cosmetology 8: 181-194. (in Korean)

Biodiversity in Korean Peninsula. 2017. Retrieved May. 15, 2017, available from https://species.nibr.go.kr.

Chinese Text Project. 2017. Retrieved May. 15, 2017, available from http://ctext.org.

Choi, K. Y. 2011. Study about species-discrimination and comparison of activity in Chang-po. $\mathrm{PhD}$ dissertation, Woosuk University, Wanju, 69 pp. (in Korean)

Chung, J. W., S. Y. Chung, S. H. Yeau, C. S. Lee, J. S. Lee, K. H. Oh, B. S. Choi, K. H. Nam, B. J. Kim, J. Y. Lee, S. H. Cho and Y. S. Kim. 2016. Interpretive Bio-resources in Chosen Dynasty (I-IV). National Institute Biological Resource, Incheon, I, 247 pp, II, 339 pp, III, 272 pp, IV, 438 pp. (in Korean)

Chung, T. H., D. B. Do and H. J. Shim. 1949. Plant Names of Joseon. Society of Biology of Joseon, Seoul, 119 pp. (in Korean)

Chung, T. H., B. S. Do, D. B. Lee and H. J. Lee. 1937. Botanical Names of Joseon. Society of History of Joseon, 222 pp. (in Korean)

Chung, Y. H., H.-K. Choi, B.-Y. Sun, Y. C. Chung and K.-J. Kim. 1986. The history of vascular plants in Korea. In Introduction to the Historical Study of Korea Plant Taxonomy. Chung, Y. H. (ed.), Academy Publishing Co., Seoul. Pp.1-190. (in Korean)

Database in Korean History. 2017. Retrieved May. 15, 2017, available from http://db.history.go.kr/.

DB of Korean Classics. 2017. Retrieved May. 15, 2017, available from http://db.itkc.or.kr/itkcdb/mainIndexIframe.jsp\#.

Flora of China in Chinese. 2017. Retrieved May. 15, 2017, available from http://frps.eflora.cn/.

Flora of China in English. 2017. Retrieved May. 15, 2017, available from http://www.efloras.org/.

Information System of Korean History. 2017. Retrieved May. 15, 2017, available from http://www.koreanhistory.or.kr/.

Jin, G.-H. 2015. Translation errors in "the Manners and Customs" Section of Gyoungdojapji. Journal of Korean Classics 46: 203-227. (in Korean)

Jo, J. E., A. Y. Lee, H. S. Kim, B. C. Moon, Y. Ji, J. M. Chun and H. K. Kim, 2013. Classification and comparative analysis of the contents of Acorus species and Anemone altaica by UPLC-PDA analysis. Korean Journal of Food Science and Technology 45: 279-284. (in Korean) 
Jo, S. O. 1982. Study of Chajapyogi system in Hyangyakchaechwiwollyeong. MS thesis, Dankuk University, Seoul, 114 pp. (in Korean)

Jung, K.-Y., B.-H. Kho and I.-B. Song. 1999. The bibiographical investigation of effect of Acorus gramineus Soland. Journal of Sasang Constitutional Medicine 11: 241-252. (in Korean)

Kim, D.-G. and S.-I. Lee. 1987. The bibiographical investigation of the origin of Acorus species. The Korea Journal of Herbology 2: 91-94. (in Korean)

Kim, I.-G. 2015. A study of traditional organism classification and its literature materials. Korean Studies Quarterly 38: 117-161. (in Korean)

Ko, S. C. 2007. Acoraceae Martinov. In The Genera of Vascular Plants of Korea. Park, C.-W. (ed.), Academy Publishing Co., Seoul. P. 1095.

Kong, K.-S. 2016. An observation of the classic plant name "Hwe". Munhwajae Korean Journal of Cultural Heritage Studies 49: 96-113. (in Korean)

Kong, K.-S. 2017. A study on the classical plant name DooChung. Gunjiinmunhag 18: 5-30. (in Korean)

Korean Plant Names Index. 2017. Retrieved May. 15, 2017, available from http://www.nature.go.kr/kpni/index.do.

Lee, C. S., S. H. Yeau and S. Y. Chung. 2016. Study of traditional plants of Jeju Island: five literatures in Joseon Dynasty period. Korean Journal of Plant Resources 29: 225-234. (in Korean)

Lee, D. C. 1993. History of Relations between Chinese and Korean Language. Seokwanghaksuljaryosa, Seoul, 462 pp. (in Korean)

Lee, E.-K. 1994. Several problems in the interpretation of Chajapyogi of Hyangyak. The Journal of Korean Language and Literature Education 26: 133-158. (in Korean)

Lee, W. T. 1996. Lineamenta Florae Koreae. Academy Publishing Co., Seoul, 2383 pp (in Korean)

Lee, W. T. 2005. The Origin of Korean Plant Names. Iljogak, Seoul, 726 pp. (in Korean)

Mori, T. 1922. An Enumeration of Plants Hitherto Known from
Corea. The Government of Chosen, Seoul, 624 pp.

Murata, S. 1932. Botanical Dictionary of Korean and Manchuria. Mesirokaku Showing, Tokyo, 778 pp. (in Japanese)

Paeng, C. H. 2014a. Plants in Chinese literature which are recognized as different plants by Koreans. Chinese Literature 81: 107-123. (in Korean)

Paeng. C. H. 2014b. Plants in Chinese literature which are recognized as different plants by Koreans (2). Journal of Chinese Language and Literature 67: 65-84. (in Korean)

Paeng, C. H. 2015. Transformation during the translation of the name of things(Mulmueong) in Chinese literatures. Theses of Korean Studies 43: 213-237. (in Korean)

Park, M. K. 1949. Plant Name in Korea. Ministry of Education, Seoul, 340 pp. (in Korean)

Park, S. B. 2006. Sukchangpo. Changsung Gunmin Sinmun (May 4, 2006). (in Korean)

Shin, H. C., H.-C. Ki and S.-J. Hong. 2015. Taxonomic identity of Chinese plant name Sam in Korean classics. Korean Studies Quarterly 38: 235-260. (in Korean)

Shin, H. C., H.-C. Ki and S.-J. Hong. 2016. Taxonomic identity of Chinese letter Chu in Shijing and its Korean translation. Journal of Chinese Language and Literature 75: 169-202. (in Korean)

Shin, H. C. 2014. Clarification of the taxonomic identities of plants for the re-understanding the traditional culture: special emphasis on plant name, 'San-su-yoo'. The Journal of Korean Traditional Cultural Heritage 13: 185-208. (in Korean)

Shin, M. K., K. Park and W. J. Maeng. 1989. Korean Translation Edition of Hyangyak jipseongbang <III $>$ (translantion). Youngrimsa, Seoul, 692 pp. (in Korean)

Son, B. T. 1996. The study of words of the name of Botanical Hyangyak. Hanminjok Emunhak 30: 105-191. (in Korean)

Yu, S. M. 2012. Development of chemical fingerprint for Acorus species by compared with extraction methods-GC/MS: determination of essential oils. MS Thesis, Kyunghee University, Seoul 54 pp. (in Korean) 